\title{
Sulforaphane inhibits TGF- $\beta$-induced epithelial-mesenchymal transition of hepatocellular carcinoma cells via the reactive oxygen species-dependent pathway
}

\author{
JINSHENG WU ${ }^{1}$, JINGLI HAN ${ }^{2}$, BENXIN HOU $^{3}$, \\ CHENGWEI DENG $^{1}$, HUANLIANG WU ${ }^{1}$ and LIANGFANG SHEN ${ }^{4}$ \\ ${ }^{1}$ Department of Oncology, Nonkennada Hospital, Danzhou, Hainan; ${ }^{2}$ The Sixth Affiliated Hospital of Xinjiang \\ Medical University, Xinjiang; ${ }^{3}$ Department of General Surgery, The Third People's Hospital of Hainan Province, Hainan; \\ ${ }^{4}$ Department of Oncology, Xiangya Hospital, Central South University, Hunan, P.R. China
}

Received November 24, 2015; Accepted December 31, 2015

DOI: $10.3892 /$ or.2016.4638

\begin{abstract}
Sulforaphane is recognized as a safe antitumor agent derived from various cruciferous vegetables, including broccoli. It has been demonstrated that sulforaphase is a potent antitumor agent in diverse cancers. However, its effect on hepatocellular carcinoma remains largely unknown. Here, we show that sulforaphane inhibits TGF- $\beta$ induced epithelial-mesenchymal transition of hepatocellular carcinoma cell via the reactive oxygen species-dependent pathway. We found sulforaphane inhibited hepatocellular carcinoma cell proliferation in a dose- and time-dependent manner. Sulforaphane induced G0/G1 phase cell cycle arrest and promoted cell apoptosis. A set of experiments showed that sulforaphase inhibited hepatocellular carcinoma cell migration and invasion, inhibited the formation of fibroblast like mesenchymal cells and the expression of Vimentin, but increased the expression of E-cadherin, suggesting sulforaphane suppresses epithelial-mesenchymal transition (EMT) process. Cotreatment with N-acetyl-L-cysteine inhibited sulforaphane-inhibited invasion and upregulation of E-cadherin and almost completely abolished the sulforaphane-induced expression of Vimentin. The effect of sulforaphane on the growth of hepatocellular carcinoma cells was confirmed by a xenograft tumor growth model. All our finding indicated that sulforaphane is a promising and safe strategy for treating hepatocellular carcinoma.
\end{abstract}

Correspondence to: Professor Liangfang Shen, Department of Oncology, Xiangya Hospital, Central South University, Hunan, P.R. China

E-mail: 1fshen2008@163.com

Key words: sulforaphane, epithelial-mesenchymal transition, apoptosis, reactive oxygen species, hepatocellular carcinoma

\section{Introduction}

Liver cancer has high incidence worldwide, and especially in China (1). Hepatocellular carcinoma represents 70-90\% of primary liver cancers occurring worldwide, it is highly aggressive with poor prognosis resulting in high mortality. Although the risk of liver cancer has been reduced with the use of antiviral treatment, they are costly and not in wide use $(2,3)$, there are no well-established effective adjuvant therapies for hepatocellular carcinoma (4). Recent advances in understanding the molecular pathogenesis of hepatocellular carcinoma have shown great promise to develop more effective treatment for hepatocellular carcinoma $(5,6)$. For this purpose, researchers have focused on the mechanism of hepatocellular carcinoma progression and metastasis, to identify better molecular targets and agents.

It has demonstrated that multiple steps are involved in the process of cancer progression and metastasis (7-9). Metastasis, one of the most complicated and major pathologic processes, is responsible for poor prognosis of cancer patients. Transforming growth factor $\beta 1$ (TGF- $\beta 1$ ) is one of the important cytokines involved. By stimulation of TGF- $\beta$, hepatocellular carcinoma HepG2 cells showed morphological, molecular and functional changes, including the formation of spindle shape, the loss of cell contact, and the downregulation of E-cadherin expression, but upregulation of Vimentin expression, showing a typical epithelial-mesenchymal transition (EMT) $(10,11)$. EMT plays an important role in various cancer metastasis, and is thought to be a prerequisite for tumor cell invasion and metastasis (12-15). Although increased evidence shows that TGF- $\beta$ could induce the EMT of various cancer cells and that EMT is pivotal for controlling tumor invasiveness and metastasis, the regulation mechanism of EMT is still unclear (16). Studies of the regulation mechanism of EMT are important for developing more effective anti-metastatic strategies.

Sulforaphane (SFN), a naturally occurring isothiocyanate derived from cruciferous vegetables, especially broccoli, which has been widely used for treatment of inflammatory diseases, shows antitumor effects in vitro and in vivo studies (17-20). Increased evidence shows that SFN is an important 
candidate cancer preventive agent with high activity in diverse cancers, including thyroid cancer (17), breast cancer (19), colon cancer $(21,22)$, prostate cancer $(18)$, bladder cancer $(23,24)$ and leukemia (25). Mechanically, it was demonstrated that SFN inhibited thyroid cancer cell growth and invasiveness, promoting mitochondrial-mediated apoptosis via reactive oxygen species (ROS)-dependent pathway (1). SFN induces apoptosis in bladder cancer cells through a ROS-mediated mitochondrial pathway $(23,24)$. Although the antitumor effect of SFN on hepatocellular carcinoma remains unknown, ROS has been also reported to mediate many cellular effects of hepatoma cells, including the EMT of HepG2 cells induced by the tumor promoter 12-O-tetradecanoyl phorbol-13-acetate (26).

The purpose of this study was to evaluate the effect of SFN on cell apoptosis, migration and invasion of hepatocellular carcinoma, as well as EMT induced by TGF- $\beta$. We also tested whether ROS involved in the antitumor mechanisms of SFN by the ROS scavenger N-acetyl-L-cysteine (NAC) and to test its in vivo therapeutic potential in hepatocellular carcinoma.

\section{Materials and methods}

Cell culture. Human hepatocellular carcinoma cell line HepG2 was obtained from ATCC (Rockville, MD, USA). Cells were cultured in RPMI-1640 medium with $10 \%$ fetal bovine serum (FBS) at $37^{\circ} \mathrm{C}$ in a humidified atmosphere containing $5 \% \mathrm{CO}_{2}$ and experiments were done using 70-80\% confluent cultures.

Cell proliferation assay. HepG2 cell survival was evaluated using the MTT (3-(4,5-dimethyl-thiazol-2-y1) 2,5-diphenyltetrazolium bromide) (Sigma, USA) colorimetric assay. After different doses (vehicle, 10, 20, 40, 60 and $80 \mu \mathrm{M}$ ) of SFN treatment for $48 \mathrm{~h}$, MTT assay was performed on hepatocellular carcinoma cell line HepG2 to evaluate cell growth ability and to calculate the $50 \%$ inhibitory concentration of SFN. Then, the cell proliferation in the presence of indicated $\mathrm{SFN}\left(\mathrm{IC}_{50}\right)$ or vehicle control for indicated time-points. In brief, prior to the treatment, HepG2 cells were seeded in 96-well tissue culture plates at $2 \times 10^{4}$ cells per well. After treatment, cells were washed with PBS and incubated in $100 \mu 1$ of $5 \mathrm{mg} / \mathrm{ml}$ MTT solution (Invitrogen Inc., USA) for $3 \mathrm{~h}$. MTT is converted into purple colored formazan in living cells which was then solubilized with dimethylsulfoxide (DMSO) (Invitrogen Inc.) and absorbance of solution was evaluated at $450 \mathrm{~nm}$ using the microplate reader Thermo Plate (Rayto Life and Analytical Science C. Ltd., Germany).

Cell cycle analysis. After treatment, cells were harvested, trypsinized and rinsed 3 times with buffer solution with adjusted concentration of $1 \times 10^{6}$ cells $/ \mathrm{ml}$ and prepared using Cycletest ${ }^{\mathrm{TM}}$ Plus DNA Reagent kit (Becton-Dickinson, USA) according to the manufacturer's instructions. Cell cycle status was analyzed by flow cytometer using propidium iodide (PI) as a specific fluorescent dye probe. The PI fluorescence intensity of 10,000 cells was measured for each sample using a Becton-Dickinson FACSCalibur flow cytometer.

Cell apoptosis assay. Cell apoptosis was determined by Annexin V assay. After transfection for $48 \mathrm{~h}$, cells were harvested by trypsinization and washed with PBS, and suspended in Annexin V binding buffer. FITC-conjugated Annexin V and propidium iodide (PI; Beyotime, China) were added to the cells successively. After incubation, Annexin V binding buffer was added, and cells were analyzed by a FACScan (Becton-Dickinson) flow cytometry. Annexin $\mathrm{V}(+) / \mathrm{P}(-)$ and Annexin $\mathrm{V}(+) / \mathrm{P}(+)$ represent the cells in early apoptosis and late apoptosis/necrosis, respectively.

Cell migration and invasion assay. Cell migration and invasion were assayed using a Transwell chamber (Millipore, USA). For the invasion assay, Transwell chamber was coated with $30 \mu \mathrm{l}$ Matrigel and was placed into 24-well plate and incubated for $30 \mathrm{~min}$ at $37^{\circ} \mathrm{C}$. After $48 \mathrm{~h}$ of transfection, HepG2 cells were trypsinized and seeded in chambers at the density of $8 \times 10^{4}$ cells per well and cultured in medium with RPMI-1640 medium with $2 \%$ serum, while $600 \mu \mathrm{l}$ of $10 \%$ FBS-RPMI-1640 with or without TGF- $\beta$ (10 ng/ml) was added to the lower chamber. Twenty-four hours later, migrated cells were fixed with $100 \%$ methanol for $30 \mathrm{~min}$ and stained by crystal violet for $20 \mathrm{~min}$. Non-migrated cells were removed by cotton swabs. Cell images were obtained under a phase-contrast microscope (Olympus, Tokyo, Japan).

Electron microscopy. Morphological changes in cells were emulated by scanning electron microscopy. Cells were grown on plastic cover slips. After indicated treatments, fixed in $2.5 \%$ glutaraldehyde in phosphate-buffered saline (PBS, $\mathrm{pH} 7.4$ ) for $2 \mathrm{~h}$, rinsed with PBS, and dehydrated through graded ethanol (30, 50, 70, 80, 90 and $100 \%$ for $20 \mathrm{~min}$ each). Cells were transferred to amylacetate for $10 \mathrm{~min}$, critical point dried, and then coated with gold. Cells were viewed in a scanning electron microscope (Olympus).

Western blotting. Western blotting was applied to detect markers of EMT at protein level. After indicated treatments, HepG2 cells cultured on the glass slide were washed twice in ice-cold PBS, and then lysed by RIPA buffer with $1 \%$ phenylmethanesulfonyl fluoride (PMSF) and complete ${ }^{\mathrm{TM}}$ protease inhibitor cocktail (Roche Molecular Biochemical, Indianapolis, IN, USA) for $30 \mathrm{~min}$. After centrifugation at 12,000 rpm for $5 \mathrm{~min}$, supernatant was collected and protein concentrations were determined using the Bio-Rad kit (Bio-Rad Laboratories, USA). Cell lysates were separated by SDS-PAGE gel, transferred to polyvinylidene difluoride (PVDF; Millipore). Membranes were blotted with $10 \%$ non-fat milk, washed in TBS-Tween and incubated with primary polyclonal antibodies anti-E-cadherin or anti-Vimentin (1:400; Santa Cruz, USA) overnight at $4^{\circ} \mathrm{C}$. After washing with TBS-Tween, membranes were incubated with secondary antibody (horseradish peroxidase conjugated $\mathrm{IgG}$ ) for $60 \mathrm{~min}$ at room temperature. Polyclonal anti-GAPDH (1:800; Bioss, China) was used as an internal control. Then, they were washed again with TBS-Tween before using the enhanced chemiluminescence detection system (Amersham Pharmacia Biotech, USA). Blots were imaged by Molecular Image ${ }^{\circledR}$ ChemiDoc $^{\text {TM }}$ XRS+ with Image Lab ${ }^{\text {TM }}$ Software (Bio-Rad Laboratories, Inc.).

Xenograft tumor model in nude mice. Five-week-old female Balb/c athymic nude mice (Vitalriver Laboratory Animals, Beijing, China) were subcutaneously injected in the right flank with $3.0 \times 10^{6} \mathrm{HepG} 2$ cells in $0.1 \mathrm{ml}$ PBS. Once tumors grew to 

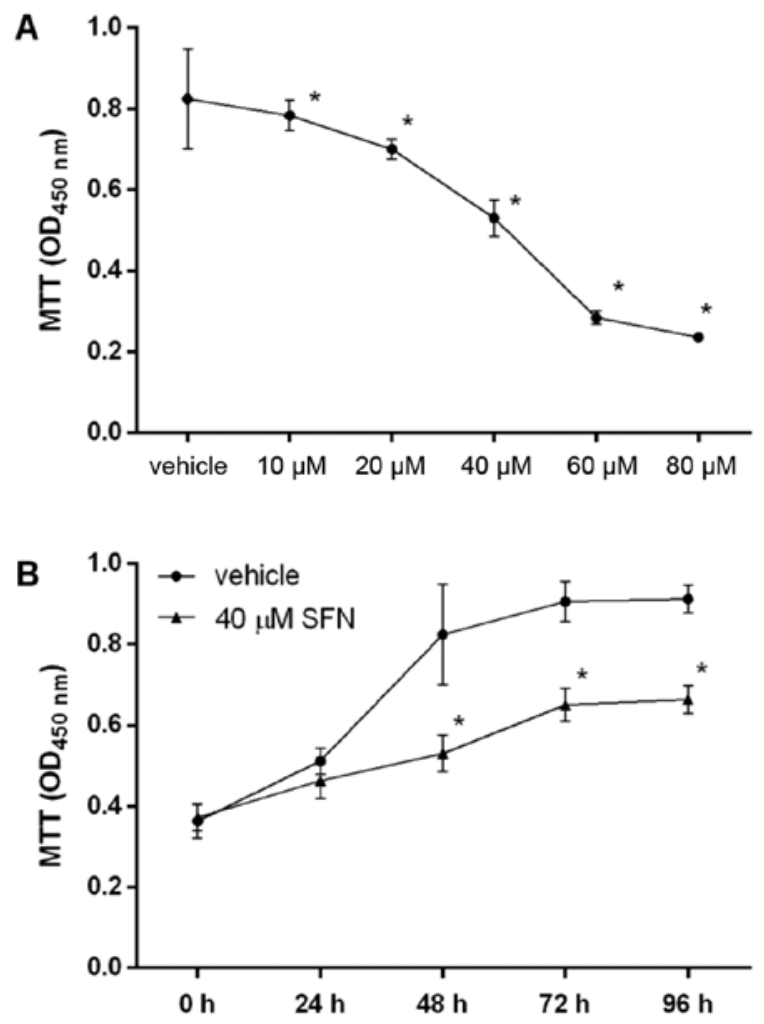

Figure 1. SFN inhibits hepatocellular carcinoma cell proliferation. (A) After different doses (vehicle, 10, 20, 40,60 and $80 \mu \mathrm{M}$ ) of SFN treatment for $48 \mathrm{~h}$, MTT assay was performed on hepatocellular carcinoma cell line HepG2 to evaluate cell growth ability. The 50\% inhibitory concentration of SFN was calculated $\left(\mathrm{IC}_{50}, 40.05 \mu \mathrm{M}\right)$. ${ }^{*} \mathrm{P}<0.05$ vs. vehicle control. (B) Then, HepG2 cells were treated with $40 \mu \mathrm{M}$ SFN or vehicle control for $48 \mathrm{~h}$, and the cell proliferation at the indicated time-points were measured by MTT assay. ${ }^{*} \mathrm{P}<0.05$ vs. $0 \mathrm{~h}$.

$\sim 5 \mathrm{~mm}$ in diameter, tumor volume (V) was measured by caliper daily and calculated using the formula $\mathrm{V}=\left(\mathrm{LxW}^{2}\right) / 2$, where $\mathrm{L}$ was the length and $\mathrm{W}$ was the width of the tumor. The mice were randomly divided into two groups $(n=6)$ for treatment with SFN $(50 \mathrm{mg} / \mathrm{kg})$ or vehicle control through i.p. injection every 2 days, respectively. Growth curves were plotted using average tumor volume within each experimental group every 2 days. Thirteen days later, the mice were euthanized, and the dissected tumors were collected and prepared for subsequent analyses. All animal experiments were approved by the animal center.

Statistical analysis. The data are presented as the mean \pm SD from the three independent experiments. Immunoblot signals were quantitated using densitometry and ImageJ software version 1.4 (NIH, USA). Statistical analysis was performed by the SPSS version 18.0 (SPSS Inc., Chicago, IL, USA) using analysis of variance (ANOVA) followed by the Tukey's t-test. $\mathrm{P}<0.05$ was considered statistically significant.

\section{Results}

SFN suppresses proliferation of hepatocellular carcinoma HepG 2 cells. The dose and time course of the effect of SFN on cell proliferation was examined by MTT assay (Fig. 1). We found that SFN significantly inhibited cell proliferation of HepG2 in a dose-dependent manner, with an $\mathrm{IC}_{50}$ value of $40.05 \mu \mathrm{M}$. HepG2 also responded to $\mathrm{SFN}$ in a time-dependent manner. SFN significantly inhibited proliferation of HepG2 cells at $40.05 \mu \mathrm{M}$ after $48 \mathrm{~h}$. Thus, SFN inhibited the proliferation of hepatocellular carcinoma HepG2 cells both dose- and time-dependently.

SFN promotes cell cycle arrest and apoptosis in hepatocellular carcinoma HepG2 cells. As the growth inhibition of cancer cells is usually associated with cell cycle arrest, the effect of SFN on cell cycle distribution of HepG2 was examined (Fig. 2A and B). We found that cell cycle was arrested at the G0/G1 phase when HepG2 cells were treated with $40 \mu \mathrm{M}$ SFN for $48 \mathrm{~h}$.

Next, we tested the effect of SFN on HepG2 cell apoptosis (Fig. 2C and D). SFN markedly increased both the early and late apoptosis, compared with control.

SFN changes the morphology and TGF- $\beta$-induced EMT of HepG2 cells. Morphology of HepG2 cells was changed in the presence of SFN (Fig. 3A). SFN suppressed the typical morphology changes of EMT induced by TGF- $\beta$, and inhibited the formation of fibroblast-like mesenchymal cells in HepG2 cells.

Phenotypic transition of SFN-inhibited EMT was further evaluated by changes of the mesenchymal marker Vimentin, and the epithelial marker E-cadherin. As expected, SFN significantly suppressed the expression of Vimentin, and significantly elevated the expression of E-cadherin (Fig. 3B). The effect of SFN on the expression of these EMT markers was in a dose-dependent. Overall, SFN inhibited TGF- $\beta$ induced EMT of HepG2.

SFN inhibits HepG2 cell migration and invasion. Using Transwell assay, the effects of SFN on cell migration and invasive ability was determined (Fig. 4A). We found a significantly decreased number of migrated HepG 2 cells treated with $40 \mu \mathrm{M}$ of SFN (Fig. 4B).

ROS-dependent mechanism mediated the effect of SFN on EMT in HepG2 cells. To evaluate whether ROS was involved in TGF- $\beta$-induced HepG2 cell migration and invasion, and EMT, ROS scavenger N-acetyl-L-cysteine (NAC, $20 \mathrm{mM}$ ) was added to treat the HepG 2 cells for $24 \mathrm{~h}$ in the present of TGF- $\beta$ (Fig. 4C-E). The inhibitory effect of SFN on migration and invasion were almost completely abolished by NAC in HepG2 cells (Fig. 4C and D). Also, NAC abolished the decrease of Vimentin, and the increase of E-cadherin (Fig. 4E). It was suggested that ROS-dependent mechanism mediated the effect of SFN on EMT of HepG2 cells.

SFN suppresses xenograft tumor growth. We showed a significant inhibitory effect of SFN on cell growth of HepG2 cells. Here, we further determined the effect of SFN on the growth of HepG2 cell-derived xenograft tumors in nude mice (Fig. 5). HepG2 cell-derived xenograft tumor grew slowly in the mice treated with $50 \mathrm{mg} / \mathrm{kg} \mathrm{SFN}$, whereas grew progressively in the control mice with a larger tumor volume than the SFN group. Taken together, our results indicate that SFN is an effective agent for hepatocellular carcinoma treatment. 

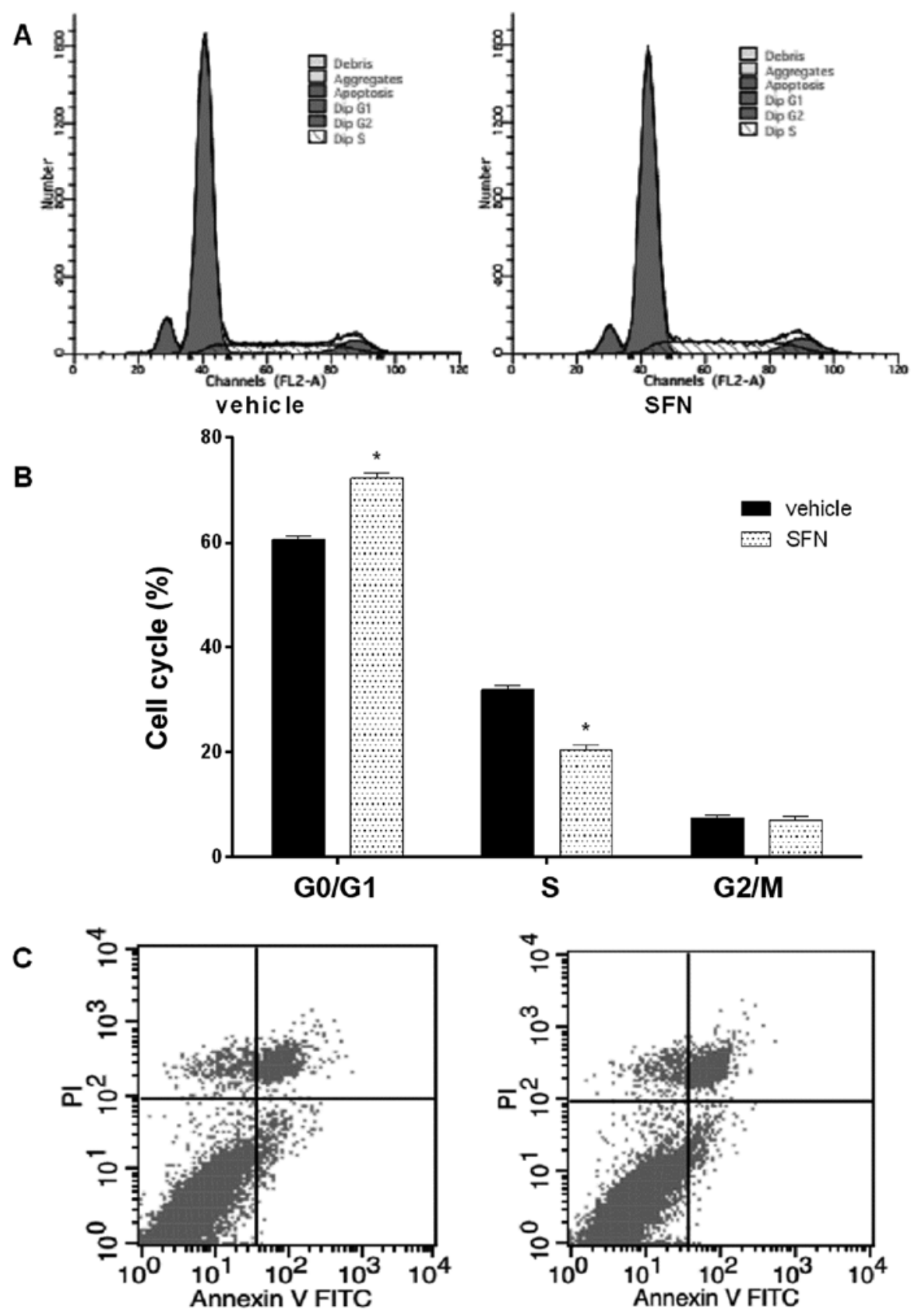

vehicle
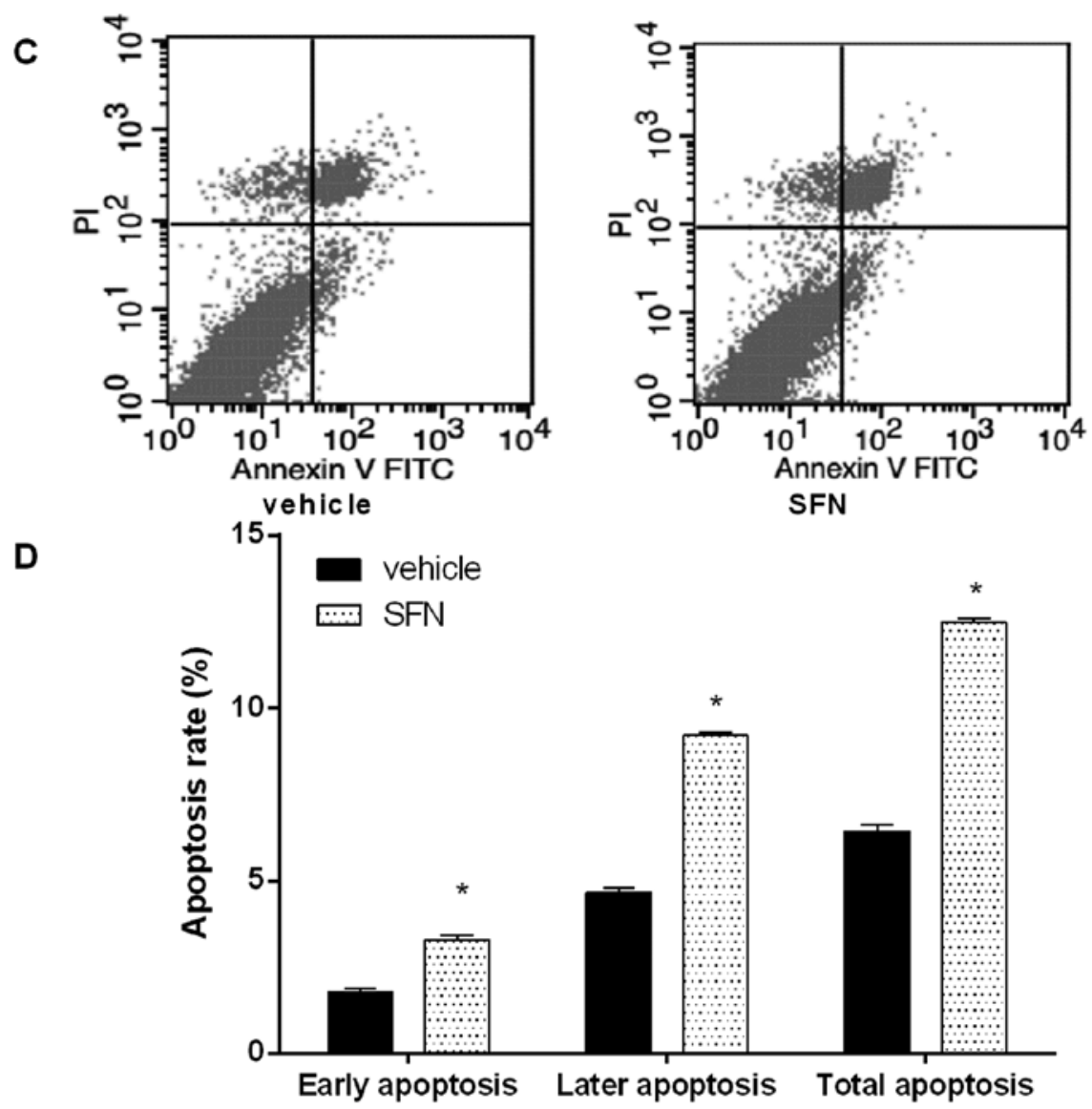

Figure 2. SFN induces hepatocellular carcinoma cell cycle arrest and cell apoptosis. HepG2 cells were treated with $40 \mu \mathrm{M}$ SFN or vehicle control for $48 \mathrm{~h}$. Then, (A) the cell cycle distribution was measured by flow cytometry, and (B) and the cell cycle phase is shown in a bar graph with the G0/G1, S and G2/M phases. (C) Cell apoptosis was determined using the Annexin V-FITC/PI flow cytometry, and (D) proportion of apoptosis cells was measured. "P $<0.05$ vs. vehicle control. 
A

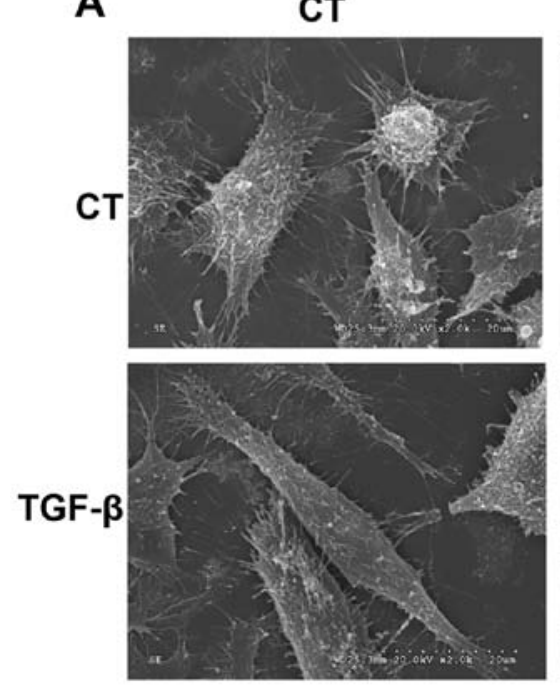

SFN
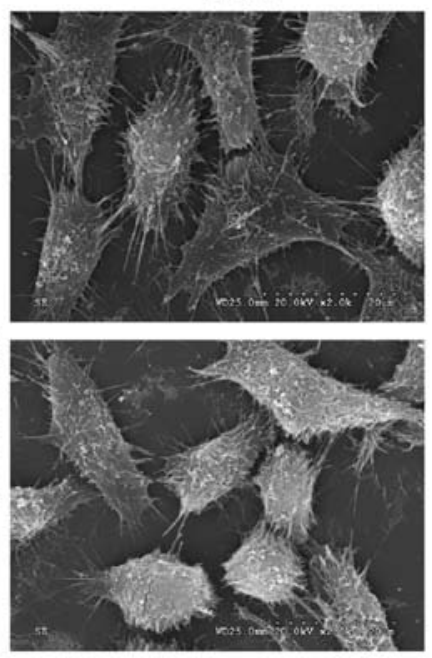

B

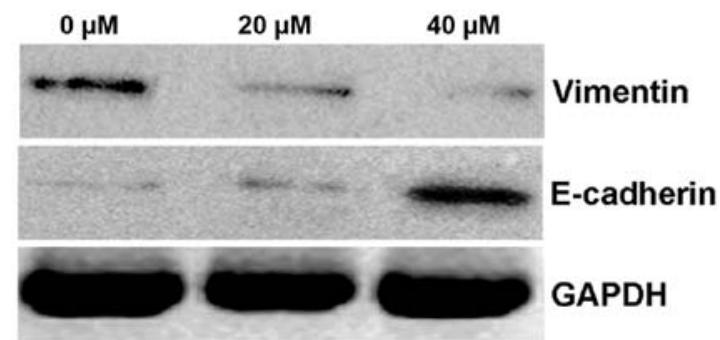

Figure 3. SFN inhibits TGF- $\beta$-induced EMT of hepatocellular carcinoma cells. TGF- $\beta$ (10 ng/ml) was used to induce EMT of HepG2 cells. After 24 h, an additional $40 \mu \mathrm{M}$ SFN and/or $20 \mathrm{mM}$ NAC was used to treat the cells for another $48 \mathrm{~h}$. (A) Morphological changes in normal cultured HepG 2 cells; TGF- $\beta$ stimulated HepG2 cells; SFN-treated HepG2 cells; TGF- $\beta$-stimulated HepG2 cells in the presence of SFN. (B) E-cadherin and Vimentin were detected by western blotting, to evaluate the effect of SFN on the EMT process of HepG 2 cells by TGF- $\beta$.

\section{Discussion}

SFN has been widely used for treatment of inflammatory diseases in vitro and in vivo (17-20). In a previous clinical study conducted on healthy volunteers (27), it was reported that no obvious abnormal events (toxicities) were observed, suggesting the safety of SFN for humans. Recent studies on the role of SFN in cancer progression indicated an antitumor effect of SFN. SFN has been reported to suppress proliferation and diverse cancer cells by causing apoptosis, cell cycle arrest, or both (28). Furthermore, SFN influenced the cell growth and metastasis in diverse cancers, including thyroid cancer (17), breast cancer (19), colon cancer $(21,22)$, prostate cancer (18), bladder cancer $(23,24)$ and leukemia $(25)$. SFN inhibited cell growth and invasiveness of thyroid cancer, and promoted mitochondrial-mediated apoptosis via reactive oxygen species (ROS)-dependent pathway (17). SFN induces apoptosis in bladder cancer cells through the ROS-mediated mitochondrial pathway $(23,24)$. However, the antitumor effect of SFN on hepatocellular carcinoma remains incompletely understood. It was demonstrated that SFN induces the generation of ROS in hepatoma cells, and sensitize many tumor necrosis factor-related apoptosis-inducing ligand (TRAIL)-resistant hepatoma cells to TRAIL-induced apoptosis by upregulating DR5 (29). ROS has been reported to mediate many cellular effects of hepatoma cells, including the EMT of HepG2 cells induced by the tumor promoter 12-O-tetradecanoyl phorbol-13-acetate (26). Our present study demonstrates that SFN significantly suppressed hepatocellular carcinoma cell growth in vitro and in vivo, and the migration, invasion and EMT of hepatocellular carcinoma cells.

As reported (17), the exact mechanism of the potent antitumor effect of SFN on cancer cells is still unclear, and the mechanism of SFN in cell cycle and apoptosis seems very complex. In T-cell leukemia and melanoma cells, SFN could induce a positive effect on p53 expression with a consequent decrease in Bcl-2 and increase in Bax $(30,31)$, whereas it is not required for the SFN activity in leukemia U937 cells and colon cancer cells $(25,32)$. In SFN-treated thyroid cancer cells, the cells were arrested in G2/M phase, which was mediated by a ROS-dependent pathway, but not a p53-dependent mechanism (17). In this study, our results showed that the cell proliferation of HepG2 were significantly decreased by treatment of SFN for $48 \mathrm{~h}$, the $50 \%$ inhibitory concentrations $\left(\mathrm{IC}_{50}\right)$ for HepG2 cells was $40.05 \mathrm{mM}$. By using $40 \mathrm{mM} \mathrm{SFN}$, the observations suggested that SFN suppressed cell proliferation of HepG2 with treatment concentration and suppressed cell growth by decreasing the cells in S phase. SFN-treated HepG2 cells were arrested in G0/G1 phase. SFN also promoted cell apoptosis. However, the underlying mechanism is still unclear, further studies will be necessary to determine the changes in $p 53$ 

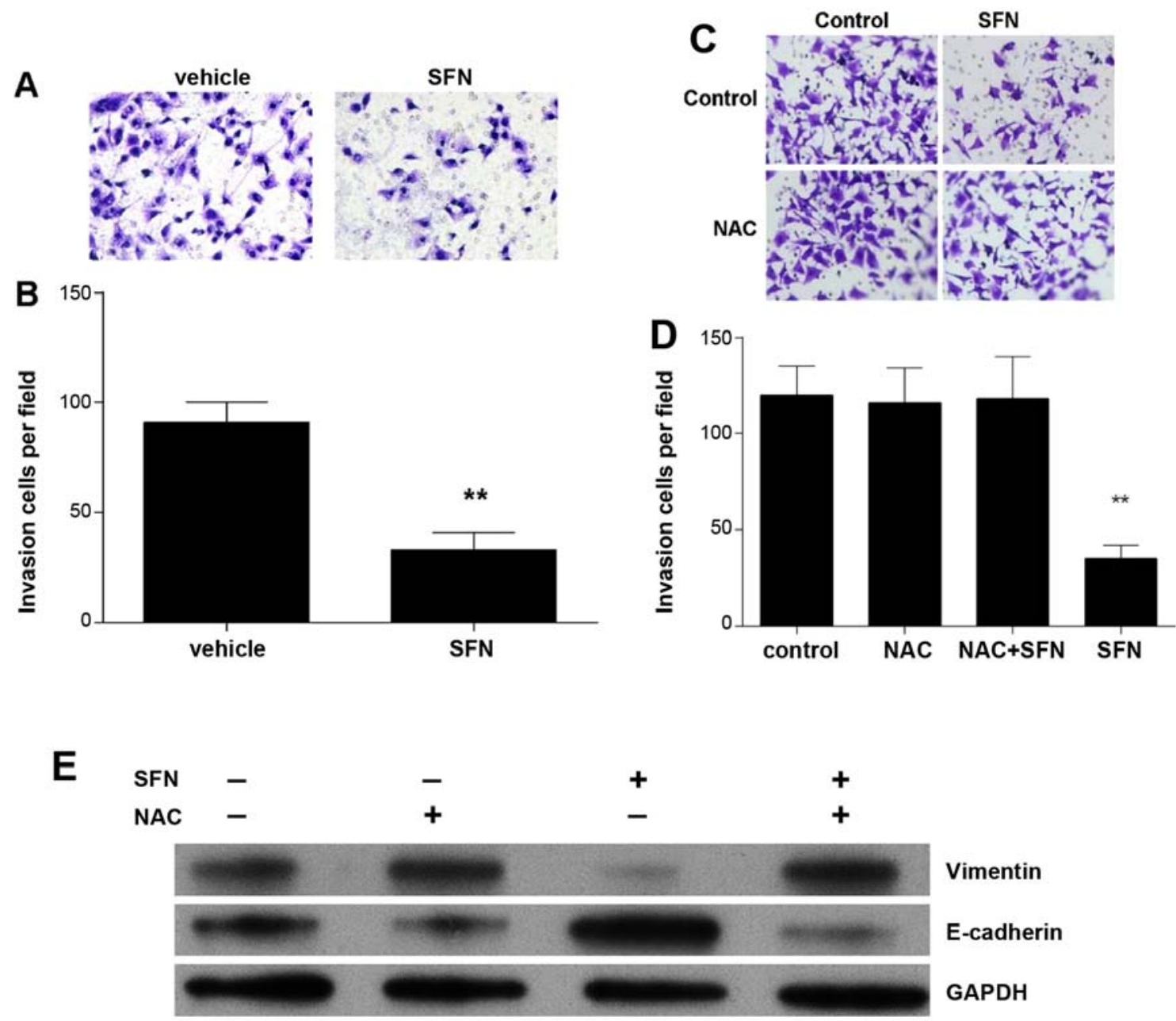

Figure 4. Effect of SFN and NAC on the TGF- $\beta$-induced EMT of hepatocellular carcinoma cells. TGF- $\beta$ (10 ng/ml) was used to induce the EMT of HepG2 cells. After $24 \mathrm{~h}$, an additional of $40 \mu \mathrm{M} \mathrm{SFN}$ and/or $20 \mathrm{mM}$ NAC was used to treat the cells for another $48 \mathrm{~h}$. (A) Migration and invasion was assessed using Transwell chamber and (B) migrated cells were counted. ${ }^{* *} \mathrm{P}<0.01$ vs. vehicle control. SFN inhibits hepatocellular carcinoma cell migration and invasion. (C) Migration and invasion was assessed using Transwell chamber and (D) migrated cells were counted. ${ }^{* *} \mathrm{P}<0.01$ vs. control. NAC abolished the inhibition of migration and invasion by SFN. (E) E-cadherin and Vimentin were detected by western blotting, to evaluate the effect of SFN with NAC on EMT process of HepG2 by TGF- $\beta$.
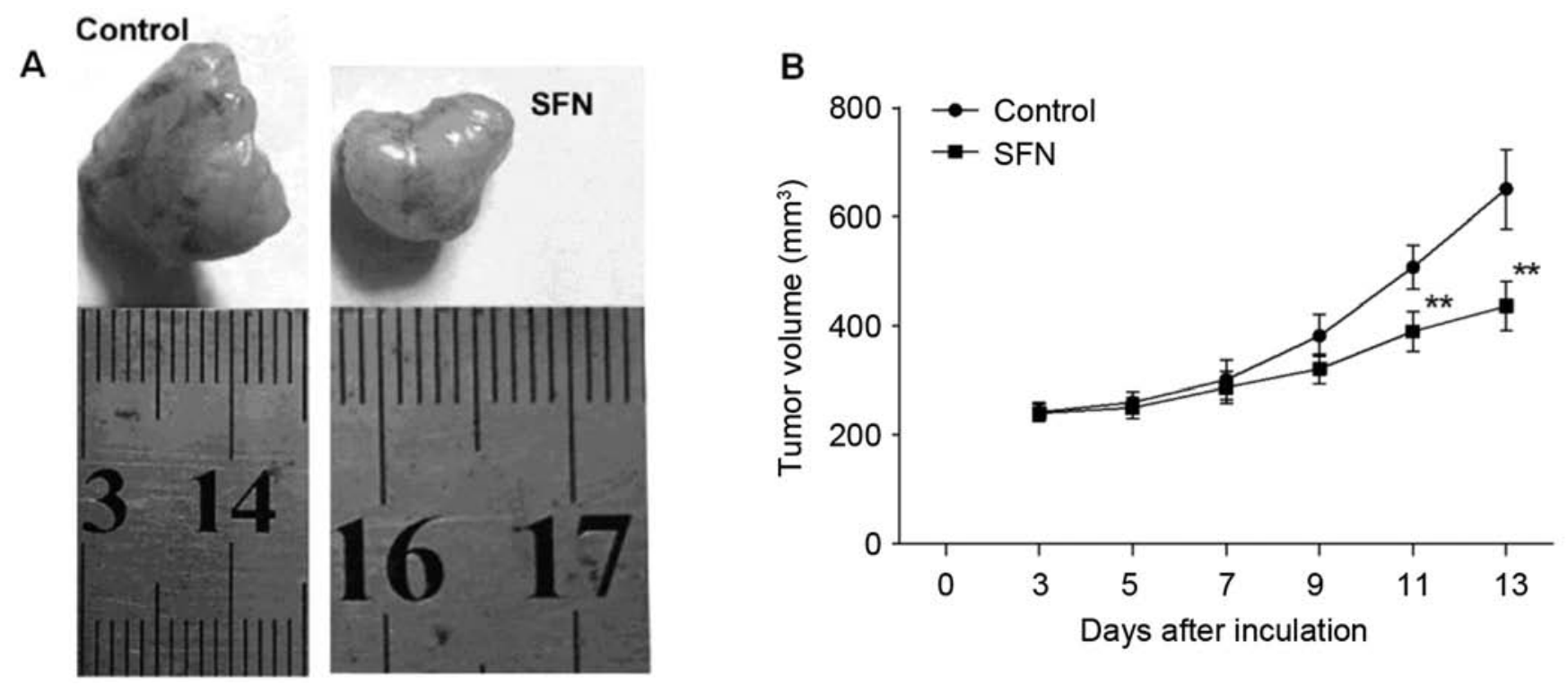

Figure 5. SFN inhibited the xenograft tumor growth. (A) Representative images of tumor growth in mice treated with control (vehicle) and $45 \mathrm{mg} / \mathrm{kg}$ of SFN. (B) Time course of the tumor volume $(\mathrm{V})$ was measured by caliper daily and calculated using the formula $\mathrm{V}=\left(\mathrm{LxW}^{2}\right) / 2$, where $\mathrm{L}$ was the length and $\mathrm{W}$ was the width of the tumor. 
proteins and ROS signaling pathway by which sulforaphane induces the cell arrest and cell apoptosis in hepatocellular carcinoma.

In recent years, EMT has been highlighted to be involved in cancer progression (33). The process of EMT is characterized as the loss of epithelial phenotype and the gain of mesenchymal phenotype (34). A recent study has showed that SFN increased expression of E-cadherin, and decreased expression of Vimentin, contributing to inhibition of EMT process of thyroid cancer cells (17). It was consistent with our finding that SFN significantly promoted the expression of E-cadherin, and reduced expression of Vimentin in hepatocellular carcinoma cells. The present study also showed the EMT of hepatocellular carcinoma cells was mediated by a ROS-dependent mechanism. The use of NAC efficiently abolished the role of SFN in migration and invasion, and in regulation of the expression of E-cadherin and Vimentin in hepatocellular carcinoma cells.

In conclusion, the present study shows that SFN inhibits hepatocellular carcinoma cell proliferation, migration and invasion, as well as EMT via a ROS-dependent pathway. The effect of SFN on the growth of hepatocellular carcinoma cells was confirmed by the xenograft tumor growth model. All our finding implicated that SFN is a promising and safe strategy for treating hepatocellular carcinoma.

\section{Acknowledgments}

This work was supported in part by the Key Project of Hainan Province, China (no. 1321320 and 67A1006) and by the Scientific Research Project of Hainan Provincial Health Department (no. Qiongwei-2012pt-92).

\section{References}

1. Torre LA, Bray F, Siegel RL, Ferlay J, Lortet-Tieulent J and Jemal A: Global cancer statistics, 2012. CA Cancer J Clin 65: 87-108, 2015.

2. Mittal S and El-Serag HB: Epidemiology of hepatocellular carcinoma: Consider the population. J Clin Gastroenterol 47 (Suppl): S2-S6, 2013.

3. Lu T, Seto WK, Zhu RX, Lai CL and Yuen MF: Prevention of hepatocellular carcinoma in chronic viral hepatitis B and C infection. World J Gastroenterol 19: 8887-8894, 2013.

4. Zhu Z, Zhang X, Wang $\mathrm{G}$ and Zheng $\mathrm{H}$ : Role of microRNAs in hepatocellular carcinoma. Hepat Mon 14: e18672, 2014.

5. Jang E, Kim BJ, Lee KT, Inn KS and Lee JH: A survey of therapeutic effects of Artemisia capillaris in liver diseases. Evid Based Complement Alternat Med 2015: 728137, 2015.

6. Mancuso A and Perricone G: Hepatocellular carcinoma and liver transplantation: State of the art. J Clin Transl Hepatol 2: 176-181, 2014.

7. Song IH: Cancer metastasis and metastasis suppressors, Korean J 43: 1-7, 2004

8. Stracke ML and Liotta LA: Multi-step cascade of tumor cell metastasis. In Vivo 6: 309-316, 1992.

9. Hu CT, Wu JR, Chang TY, Cheng CC and Wu WS: The transcriptional factor Snail simultaneously triggers cell cycle arrest and migration of human hepatoma HepG2. J Biomed Sci 15: 343-355, 2008.

10. Huber MA, Kraut N and Beug H: Molecular requirements for epithelial-mesenchymal transition during tumor progression. Curr Opin Cell Biol 17: 548-558, 2005.

11. Xu XM, Yuan GJ, Li QW, Shan SL and Jiang S: Hyperthermia inhibits transforming growth factor beta-induced epithelialmesenchymal transition (EMT) in HepG2 hepatocellula carcinoma cells. Hepatogastroenterology 59: 2059-2063, 2012.

12. Scanlon CS, Van Tubergen EA, Inglehart RC and D'Silva NJ: Biomarkers of epithelial-mesenchymal transition in squamous cell carcinoma. J Dent Res 92: 114-121, 2013.
13. Shih JY and Yang PC: The EMT regulator slug and lung carcinogenesis. Carcinogenesis 32: 1299-1304, 2011.

14. Szarvas T, vom Dorp F, Ergün S and Rübben H: Matrix metalloproteinases and their clinical relevance in urinary bladder cancer. Nat Rev Urol 8: 241-254, 2011.

15. Sullivan NJ, Sasser AK, Axel AE, Vesuna F, Raman V, Ramirez N, Oberyszyn TM and Hall BM: Interleukin-6 induces an epithelialmesenchymal transition phenotype in human breast cancer cells. Oncogene 28: 2940-2947, 2009.

16. Lamouille S, Xu J and Derynck R: Molecular mechanisms of epithelial-mesenchymal transition. Nat Rev Mol Cell Biol 15: 178-196, 2014.

17. Wang L, Tian Z, Yang Q, Li H, Guan H, Shi B, Hou P and Ji M: Sulforaphane inhibits thyroid cancer cell growth and invasiveness through the reactive oxygen species-dependent pathway. Oncotarget 6: 25917-25931, 2015.

18. Xu C, Shen G, Yuan X, Kim JH, Gopalkrishnan A, Keum YS, Nair $\mathrm{S}$ and Kong AN: ERK and JNK signaling pathways are involved in the regulation of activator protein 1 and cell death elicited by three isothiocyanates in human prostate cancer PC-3 cells. Carcinogenesis 27: 437-445, 2006.

19. Jackson SJ and Singletary KW: Sulforaphane: A naturally occurring mammary carcinoma mitotic inhibitor, which disrupts tubulin polymerization. Carcinogenesis 25: 219-227, 2004.

20. Bergantin E, Quarta C, Nanni C, Fanti S, Pession A, Cantelli-Forti G, Tonelli R and Hrelia P: Sulforaphane induces apoptosis in rhabdomyosarcoma and restores TRAIL-sensitivity in the aggressive alveolar subtype leading to tumor elimination in mice. Cancer Biol Ther 15: 1219-1225, 2014.

21. Jeong WS, Kim IW, Hu R and Kong AN: Modulatory properties of various natural chemopreventive agents on the activation of NF-kappaB signaling pathway. Pharm Res 21: 661-670, 2004.

22. Jeong WS, Kim IW, Hu R and Kong AN: Modulation of AP-1 by natural chemopreventive compounds in human colon HT-29 cancer cell line. Pharm Res 21: 649-660, 2004.

23. Jo GH, Kim GY, Kim WJ, Park KY and Choi YH: Sulforaphane induces apoptosis in T24 human urinary bladder cancer cells through a reactive oxygen species-mediated mitochondrial pathway: The involvement of endoplasmic reticulum stress and the Nrf2 signaling pathway. Int J Oncol 45: 1497-1506, 2014.

24. Park HS, Han MH, Kim GY, Moon SK, Kim WJ, Hwang HJ, Park KY and Choi YH: Sulforaphane induces reactive oxygen speciesmediated mitotic arrest and subsequent apoptosis in human bladder cancer 5637 cells. Food Chemical Toxicol 64: 157-165, 2014.

25. Choi WY, Choi BT, Lee WH and Choi YH: Sulforaphane generates reactive oxygen species leading to mitochondrial perturbation for apoptosis in human leukemia U937 cells. Biomed Pharmacother 62: 637-644, 2008

26. Wu WS, Tsai RK, Chang $\mathrm{CH}$, Wang S, Wu JR and Chang YX: Reactive oxygen species mediated sustained activation of protein kinase $\mathrm{C}$ alpha and extracellular signal-regulated kinase for migration of human hepatoma cell HepG2. Mol Cancer Res 4: 747-758, 2006.

27. Shapiro TA, Fahey JW, Dinkova-Kostova AT, Holtzclaw WD, Stephenson KK, Wade KL, Ye L and Talalay P: Safety, tolerance, and metabolism of broccoli sprout glucosinolates and isothiocyanates: A clinical phase I study. Nutr Cancer 55: 53-62, 2006.

28. Singh SV, Srivastava SK, Choi S, Lew KL, Antosiewicz J, Xiao D, Zeng Y, Watkins SC, Johnson CS, Trump DL, et al: Sulforaphaneinduced cell death in human prostate cancer cells is initiated by reactive oxygen species. J Biol Chem 280: 19911-19924, 2005.

29. Kim H, Kim EH, Eom YW, Kim WH, Kwon TK, Lee SJ and Choi KS: Sulforaphane sensitizes tumor necrosis factor-related apoptosis-inducing ligand (TRAIL)-resistant hepatoma cells to TRAIL-induced apoptosis through reactive oxygen speciesmediated up-regulation of DR5. Cancer Res 66: 1740-1750, 2006.

30. Fimognari C, Nüsse M, Cesari R, Iori R, Cantelli-Forti G and Hrelia P: Growth inhibition, cell-cycle arrest and apoptosis in human T-cell leukemia by the isothiocyanate sulforaphane. Carcinogenesis 23: 581-586, 2002.

31. Hamsa TP, Thejass P and Kuttan G: Induction of apoptosis by sulforaphane in highly metastatic B16F-10 melanoma cells. Drug Chem Toxicol 34: 332-340, 2011.

32. Rudolf $E$ and Cervinka M: Sulforaphane induces cytotoxicity and lysosome- and mitochondria-dependent cell death in colon cancer cells with deleted p53. Toxicol In Vitro 25: 1302-1309, 2011.

33. Thiery JP: Epithelial-mesenchymal transitions in tumour progression. Nat Rev Cancer 2: 442-454, 2002.

34. Guarino M, Rubino B and Ballabio G: The role of epithelialmesenchymal transition in cancer pathology. Pathology 39: 305-318, 2007. 